\title{
Eimeria burdai sp. n. (Apicomplexa: Eimeriidae), a new parasite species from subterranean African silvery mole-rat, Heliophobius argenteocinereus
}

\author{
Břetislav Koudela ${ }^{1,2}$, Radim Šumbera ${ }^{3}$ and František Sedláček ${ }^{3}$ \\ ${ }^{1}$ Institute of Parasitology, Academy of Sciences of the Czech Republic, Branišovská 31, 37005 České Budějovice, Czech \\ Republic; \\ ${ }^{2}$ Department of Parasitology, University of Veterinary and Pharmaceutical Sciences, Palackého 1-3, 61242 Brno, Czech \\ Republic; \\ ${ }^{3}$ Department of Zoology, Faculty of Biological Sciences, University of South Bohemia, Branišovská 31, 37005 České \\ Budějovice, Czech Republic
}

Key words: Apicomplexa, Eimeriidae, Eimeria burdai, Rodentia, Bathyergidae, Heliophobius argenteocinereus

\begin{abstract}
A new coccidian parasite of the genus Eimeria Schneider, 1875 is described from the subterranean African silvery mole-rat Heliophobius argenteocinereus Peters, 1846. Oocysts of Eimeria burdai sp. n. were subspherical to broadly ellipsoidal $17.8(16-19) \times 14.1(12-15)$, with a shape index $1.2(1.1-1.4)$. Oocyst wall was bilayered, smooth and colourless, approximately 1.0 thick. Outer layer was significantly thicker than inner one. A micropyle and oocyst residuum were absent. One or two ellipsoidal or spherical polar granules were present. Sporocysts were ellipsoidal, $10.8(9-12) \times 6.2(5-8)$ with a shape index 1.7 (1.5-1.9). Sporocyst wall was single-layered, thin, smooth and colourless, with small Stieda body at the pointed end. In freshly sporulated oocysts, spherical sporocyst residuum was composed of small granules enclosed by a thin membrane. Sporozoites were elongate, lying length-wise in the long axis of the sporocyst, partially curled around each other, with single large refractile body located posteriorly. Faintly distinguishable nucleus was in the central part of the sporozoite. This eimerian represents the first coccidian species described from subterranean African silvery mole-rat (Rodentia: Bathyergidae).
\end{abstract}

The family Bathyergidae includes five genera of subterranean rodents, all endemic to the sub-Saharan African region. Most of them have recently become an interesting subject for studies in ecology, taxonomy, physiology and social and sensory biology. Solitary silvery mole-rats Heliophobius argenteocinereus Peters, 1846 are widely distributed throughout East and Central-East Africa (Nowak 1991). Despite this fact, there is very little knowledge about the biology and ecology of this subterranean rodent. Here, a coccidian parasite is reported for the first time from the silvery mole-rat and is described as a new species of the genus Eimeria.

\section{MATERIALS AND METHODS}

Six adult silvery mole-rats were examined coprologically. One of them (female) was captured in Zambia (Lubalashi Area, Central Province), while the other five mole-rats were captured in Malawi. Of these latter, three females and one male were caught near the city Mulanje and one male was captured in Blantyre. The silvery mole-rats were housed individually in plastic cages in an isolated air-tight room with a heater that maintained a constant temperature of $23 \pm 1^{\circ} \mathrm{C}$, and the floor of the cages was covered with wood shavings or peat. Relative humidity ranged from 50 to $70 \%$. The mole-rats were fed potato, carrot, apple, lettuce, sweet corn, and turnip supplemented with green parts of plants.

Individual faecal samples were collected from the cage bottoms and screened for parasites using flotation in Sheather's sugar solution. When unsporulated coccidian oocysts were found, they were allowed to sporulate in Petri dishes in a thin layer of $2.5 \%(\mathrm{w} / \mathrm{v})$ potassium dichromate solution at laboratory temperature. Thirty sporulated oocysts were measured with an calibrated ocular micrometer using bright-field microscopy $(100 \times$ objective) to obtain morphologic data. All measurements are given in micrometres $(\mu \mathrm{m})$, with the mean followed by the range in parentheses. Isolated oocysts were examined and photographed using Nomarski interference contrast (NIC) microscopy.

To observe the sporulation process, fresh faecal samples were collected on two separate occasions from two animals; faeces were mixed with $2.5 \%(\mathrm{w} / \mathrm{v})$ potassium dichromate solution, poured into Petri dishes to a depth of less than $5 \mathrm{~mm}$, and incubated at $25^{\circ} \mathrm{C}$ for oocyst sporulation. The oocysts were examined every 8 hours during incubation. The sporulation process was not statistically evaluated. 


\section{RESULTS}

Our coprological examinations revealed the presence of oocysts of a previously undescribed coccidian species belonging to the genus Eimeria in 2/6 (33\%) silvery mole-rats. Oocysts were detected in the one female captured at Lubalashi (Zambia) and the second positive faecal sample was obtained from a female captured in Mulanje (Malawi).

\section{Eimeria burdai sp. n.}

Figs. 1-3

Oocysts subspherical to broadly ellipsoidal 17.8 (16$19) \times 14.1(12-15)$; shape index 1.23 (1.1-1.4). Oocyst wall bilayered, smooth and colourless, approximately 1.0 thick. Outer layer significantly thicker than inner one. Micropyle and oocyst residuum absent. One or two ellipsoidal or spherical polar granules present. Sporocysts ellipsoidal, $10.8(9-12) \times 6.2(5-8)$; shape index 1.7 (1.5-1.9). Sporocyst wall unilayered, thin, smooth and colourless, with small Stieda body at the pointed end. In freshly sporulated oocysts, spherical sporocyst residuum was present composed of small granules enclosed by a thin membrane. Sporozoites elongate, lying length-wise in the long axis of the sporocyst, partially curled around each other, with single large refractile body at posterior end. Faintly distinguishable nucleus was situated in the central part of the sporozoite.

$\mathrm{T}$ y $\mathrm{p}$ e $\mathrm{h}$ o s t : African silvery mole-rat, Heliophobius argenteocinereus Peters, 1846 (Rodentia: Bathyergidae).
Ty pe 1 o c a 1 i ty: Lubalashi Area, Zambia.

Prevale n c e : 2 of $6(33.3 \%)$.

$\mathrm{S}$ it e of in fection: Unknown. Oocysts recovered from faeces.

$\mathrm{S} p$ o r u 1 a t i o n : Exogenous. All oocysts were passed unsporulated in faeces. The granular sporont filled freshly passed oocysts. During the first $16 \mathrm{~h}$, the sporont concentrated to $13-15 \mu \mathrm{m}$ in diameter. The protoplasmic mass of the sporont contained large granules around the periphery with smaller granules in the interior. After $32 \mathrm{~h}$, most of the oocysts contained sporont with protrusions toward the periphery of the oocyst. After this stage, the protrusions gradually increased in size, became pyramidal and, finally, separated one from the other to form subspherical or oval sporoblasts. After $64 \mathrm{~h}$, the sporoblasts elongated, formed a sporocyst membrane, sporocyst residuum and Stieda body. About this time the Stieda body was formed and the refractile body appeared in each sporozoite. Oocysts were fully sporulated within $72 \mathrm{~h}$ at $25^{\circ} \mathrm{C}$.

$\mathrm{P}$ a t h o g e n i c i t y : Infected silvery mole-rats did not exhibit any signs of alteration of the health status.

T y p e m a t e r i a 1 : Phototypes are deposited at the Institute of Parasitology, Academy of Sciences of the Czech Republic, České Budějovice (No. B1/99).

E t y m o lo g y : The specific epithet is given in honour of Prof. Dr. Hynek Burda (Department of Zoology, University of Essen, Germany) in recognition of his contribution to the biology, systematics and evolution of African mole-rats (Bathyergidae).

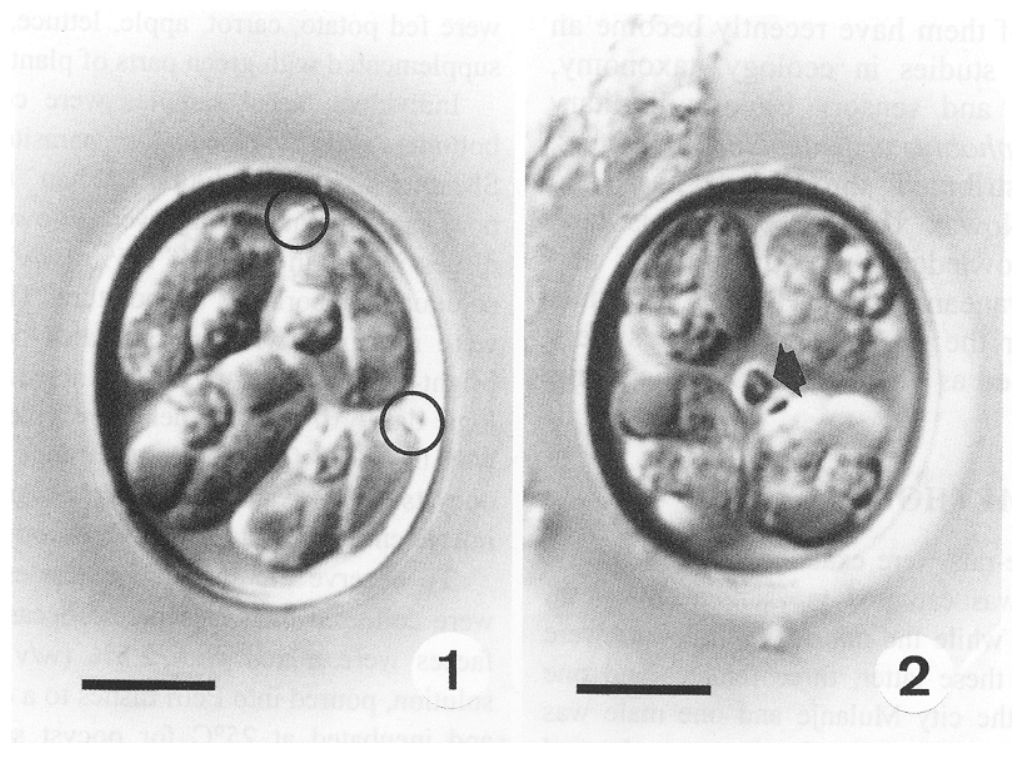

Figs. 1, 2. Nomarski interference contrast (NIC) photomicrographs of sporulated oocysts of Eimeria burdai sp. n. Fig. 1. Note the small Stieda bodies (circles). Fig. 2. Note polar granule (arrow). Scale bars: Figs. 1, $2=5 \mu \mathrm{m}$. 


\section{DISCUSSION}

The new species, Eimeria burdai, represents the first coccidian species described from the subterranean African silvery mole-rat. Previously, coccidian oocysts were found only in the naked mole-rat Heterocephalus glaber, a closely related host species. This species was called Eimeria muris (Porter 1957), and no measurements were provided. However, the only valid host for E. muris is the field mouse Apodemus sylvaticus and this species was, therefore, emended to Eimeria heterocephali (Levine and Ivens 1965). Furthermore, Porter's description and drawing are inadequate for comparison with our data. No other coccidia have been reported from any other members of the family Bathyergidae. Based on all of these known facts, $E$. burdai is here described as new species.

In the course of sporulation of E. burdai six stages can be differentiated: stage of rounded sporont, stage with protrusions, pyramidal stage, four-sporoblast stage, stage of sporozoite differentiation, and stage of complete sporulation. Sporulation of E. burdai is generally similar to that of other Eimeria species.

The members of family Bathyergidae have recently become a frequent subject for studies in physiology and social and sensory biology. One of the interesting questions related to the ecology, taxonomy and social biology of bathyergids is that of its parasites (Scharff et al. 1997). The subterranean ecotype of these animals would be expected to favour diseases and parasites (Scharff and Burda 1998), especially those with direct life cycles, and influences of subterranean and social way of life upon occurrence of parasites in bathyergids were discussed (Scharff et al. 1997). The studying of coccidian parasites may also help to understand the role of parasites in shaping the expression of social behaviour in mole-rats.

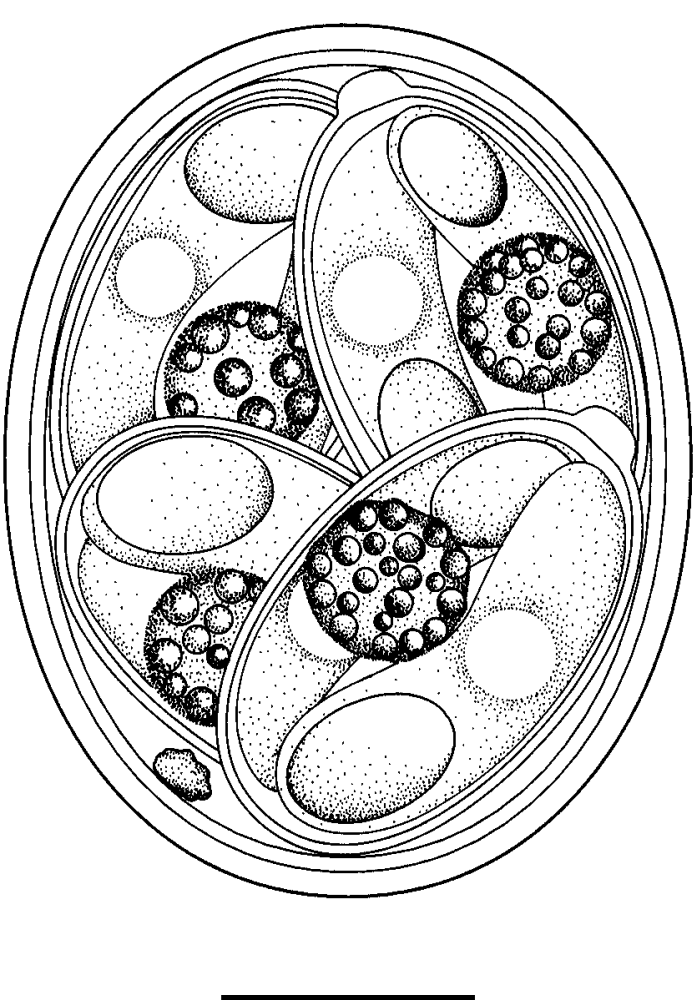

Fig. 3. Composite line drawing of sporulated oocyst of Eimeria burdai sp. n. Scale bar $=10 \mu \mathrm{m}$.

Acknowledgements. We thank Andreas Scharff and Wilbert N. Chitaukali for providing of animals and Jiří Volf and Jan Šlapeta for preparing the line drawing. The internal student research grant of Faculty of Biological Sciences, University of South Bohemia, (SGA 98/03) supported this study.

\section{REFERENCES}

LEVINE N.D., IVENS V. 1965: The Coccidian Parasites (Protozoa, Sporozoa) of Rodents. Illinois Biological Monographs 33, University of Illinois Press, Urbana, 365 pp.

NOWAK R.M. 1991: Walker's Mammals of the World. Vol. II. John Hopkins University Press, Baltimore and London, $1699 \mathrm{pp}$.

PORTER A. 1957: Morphology and affinities of entozoa and entophyta of the naked mole rat Heterocephalus glaber. Proc. Zool. Soc. Lond. 128: 515-526.

SCHARFF A., BURDA H. 1998: Eusociality, life underground and parasites. Tree 13: 199.

SCHARFF A., BURDA H., TENORA F., KAWALIKA M., BARUŠ V. 1997: Parasites in social subterranean Zambian mole-rats (Cryptomys spp., Bathyergidae, Rodentia). J. Zool. (Lond.) 241: 571-577. 